\title{
CENTERING VOICES: WEAVING INDIGENOUS PERSPECTIVES IN TEACHER EDUCATION
}

\author{
Laryssa Gorecki \\ Niagara University \\ Carol Doyle-Jones \\ Niagara University
}

\begin{abstract}
The value of weaving Indigenous perspectives into the mainstream curricula of Ontario teacher education programs is gaining prominence (Bell \& Brant, 2015; Nardozi, Restoule, Broad, Steele, \& James, 2014; Tanaka, 2016). Since the Truth and Reconciliation Commission of Canada's Calls to Action (2015), efforts are being made across Ontario to "educate teachers on how to integrate Indigenous knowledge and teaching methods into classrooms" (TRC \#62, $p$. 7). Despite growing efforts within teacher preparation programs, many settler teacher candidates are still anxious (Kanu, 2011; Morcom \& Freeman, 2019); they fear practicing inadvertent cultural appropriation, and/or offending or misinforming their students and colleagues. To address these concerns, we posed the research question: What impact would Indigenous guest speakers and workshop leaders have on helping Settler teacher candidates navigate Indigenous content in a culturally appropriate and respectful manner? Using an action research framework, we explored how Indigenous ways of knowing impacted the attitudes of teacher candidates in a Bachelor of Education program. The data we collected suggests that by listening to and learning from Indigenous teachings, teacher candidates can attain a deeper understanding of relationality (Wilson, 2008) as it applies to Indigenous ways of knowing. While certain questions remained, pre-service teachers had an increased knowledge of Indigenous content, and felt more comfortable integrating Indigenous perspectives into their classroom practice.
\end{abstract}

KEY WoRDS: Action research; Indigenous education; Indigenous perspectives; Teacher education; Relationship-building 


\section{ACKNOWLEDGEMENT}

We want to acknowledge the individuals with whom we worked in relationship: educators, storytellers, Knowledge Keepers, and artists of diverse Indigenous heritage/ancestry, including Robert Cutting (Kanienkeha'ka First Nation), Marina Ford (Shoshone First Nation \& Cherokee Nation), and Diane Montreuil (Métis Nation).

We would also like to acknowledge the original caretakers of lands of the post-secondary site where research was gathered for this study. We are situated on Traditional Territories and Treaty Lands of the Petun, Haudenosauneega (Longhouse Confederacy), Anishinabewaki, and the Mississaugas of the Credit First Nation.

\section{ConTEXT}

Indigenous scholars (Hare, 2019; Pete, 2015; Toulouse, 2016) are encouraging praxis using Indigenous ways of knowing to inform and enrich teaching practice. As part of Ontario's commitment to Reconciliation with Indigenous peoples, Ontario's Faculties of Education have been required to provide mandatory Indigenous content in Teacher Education Programs (Government of Ontario, 2016) in order "to educate teachers on how to integrate Indigenous knowledge and teaching methods into the classroom" (Truth and Reconciliation Commission of Canada, 2015).

\section{About the Authors}

We, the authors, met at a national literacy conference three years ago. We were both there to further uncover how to "conceptualize education differently" and, in particular, how to integrate Indigenous Education into our own pedagogy and into the future classrooms of our teacher candidates (TCs).

As Settler teachers of Indigenous Education, we do not aim to reproduce Indigenous knowledge, and we strive to be sensitive and inform ourselves of evolving practices and complexities in this realm. Furthermore, we do not seek to be the voice of Indigenous peoples nor do we claim to have a comprehensive understanding of Indigenous ways of being and knowing. Rather, we openly acknowledge the limitations of our knowledge base and recognize that Indigenous knowledge systems and worldviews are legitimate ways of understanding the world that have been historically oppressed by Settler institutions, including the colonial education system within which we ourselves work. We also acknowledge the critical importance of relationships when learning about, with, and from Indigenous peoples, as we understand that education is a "relational, reciprocal, and respectful process" (Archibald, 2008, p. 175).

We acknowledge the importance of ongoing critical self-reflection and positioning as primary in our journeys so that we better understand how our histories have shaped our individual worldviews. As such, we situate ourselves by exploring our own White Settler identities, including the privileges afforded to us at the expense of Indigenous peoples. This project represents an attempt at modeling for our TCs the application of our critical consciousness to scholarship, as a step of engaging in deeper relationships with one another. 


\section{Definitions and Goals}

For the purposes of this article, the term 'Indigenous' is used as a collective reference to the original peoples of North America and their descendants (Library and Archives Canada, 2017). It is important to note that this term may not always be the one used by Indigenous peoples to describe themselves (Battiste, 2013). We acknowledge the incredible diversity of Indigenous peoples, and respect the preference to be referred to by Nation and/or by Indigenous place names, and that these preferences are individual and evolving (Vowel, 2016). We use the term 'Indigenous education' to refer to "the practice of genuine and respectful education about Indigenous history, cultures, and lived experiences" (Peters, 2018, p. 3), to be considered as education for everyone (Snowball, 2014), and reflective of the inclusion of pedagogical strategies of Indigenous peoples, which, when it comes to curricular content, vary from nation to nation (Toulouse, 2016). Educators are encouraged to begin with local Indigenous communities (Overmars, 2010) when teaching curriculum content and relevant cultural examples specific to Indigenous knowledge, values, and skills.

The overall purpose of this project is for Settler teacher candidates (TCs) to accurately, effectively, and competently integrate Indigenous ways of learning and knowing into their curricula. A caveat here is that this research does not preclude the knowledge Indigenous TCs hold; the need identified for this study was for Settler TCs, as we had not identified Indigenous students in our institution. Despite the Truth and Reconciliation Commission of Canada's (TRC) Calls to Action, many Settler learners still do not have sufficient opportunities to gain a deeper understanding of the histories and cultures of Indigenous nations to confidently teach the material (Kanu, 2011; Nardozi \& Mashford-Pringle, 2014); however, we have witnessed a growing momentum of emerging initiatives around Indigenous Education (Morcom \& Freeman, 2019; Poitras Pratt \& Hanson, 2020). As such, one of the goals for this project was to provide meaningful opportunities to promote engagement and understanding of Indigenous ways of knowing as a step towards "ally-building" (Morcom \& Freeman, 2018, p. 830), and becoming confident and well-informed enough to develop appropriate content to bring Indigenous concepts into their classrooms. We therefore developed the research question: "What impact would Indigenous guest speakers have on helping Settler TCs navigate Indigenous content in culturally appropriate and respectful ways?"

\section{Decolonizing Teacher Education}

Madden (2015) asserts that it is the responsibility of all teacher educators to familiarize themselves with, and to take into account, the framework for Indigenous education used within their institution. This study is a response to the TRC's Calls to Action, and a commitment to personal and professional reconciliation and decolonization of teacher educator practice.

McGregor (2012) defines 'decolonizing pedagogies' as “teaching and learning approaches that both acknowledge and deconstruct structures of power associated with colonization in an effort to create space for, and give legitimacy to, Indigenous ways of knowing, being and doing" (p. 13). As White Settler educators, we feel a strong responsibility to find a 
meaningful way to enact this in our practice. Our approach is praxis-oriented and grounded in awareness of how Canada's educational institutions have largely ignored Indigenous knowledge and pedagogy (Battiste, 2005), as well as how Indigenous perspectives have been experienced through a colonized worldview. We recognize past colonial efforts to eradicate Indigenous peoples through institutional practices (Battiste, 2005); as a result, our actions are oriented toward decolonizing education approaches. As Battiste (2005) attests, "the next step needed in the quest [to balance European and Indigenous ways of knowing] is a deeper understanding of Indigenous knowledge" (p. 5).

\section{Relationship-Building \& Co-Learning}

Our current roles as teacher educators working with TCs who were engaged in coursework with a focus on Indigenous Education highlighted our evolving understanding of both what decolonizing pedagogy and relationship-building might actually look like for them in a classroom setting, as well as their own role as teachers in relation to these concepts. Building relationships with Indigenous Peoples entails "holding space for Elders, Knowledge Keepers, and those who hold community knowledge, to be invited to provide authentic voice in learning" (Ontario Ministry of Education's Approach to Indigenous Education, 2020). Our project is one attempt at creating a bridge for building a relationship between Indigenous and non-Indigenous peoples. It emphasizes that in order to respectfully and authentically weave Indigenous perspectives into the classroom, TCs need to attain a deeper awareness of, and greater comfort level with, how relationality (Wilson, 2008) applies to Indigenous ways of knowing and learning. Wilson brings together three R's -- respect, reciprocity and relationality -- into the concept of "relational accountability" (p. 99), wherein researchers consider their relations in choosing topics to research, and being accountable to these relationships as data is collected and carried out. Informed by this, we aimed to pursue an outcome that goes beyond the giving of a gift to the Indigenous presenters (Weber-Pillwax, 2001); we hoped to cultivate relational partnerships through dialoguing with them.

As part of our initial envisioning, we were informed by McGregor and Marker (2018), who outline several possibilities associated with pursuing reciprocal relationships in a university setting. One idea reinforced through our project is that "reciprocity may be pursued in transactions with participants, sometimes after the research is completed (i.e. the "give back"), but end up hidden to those who later read the resulting research" (p. 320). This project is only the first step in our efforts of cultivating relationships with Indigenous peoples, and, as Kuokkanen (2011) encourages, integrating Indigenous views of reciprocity in the "circular form" (p. 37). Circular reciprocity keeps gifts circulating, to "actively acknowledge kinship and coexistence with the world" (p. 38). Hence, we believe that our continued efforts of building relationships with Indigenous colleagues (i.e. co-hosting annual Indigenous education conferences), and holding space for their voices, we are, "giving back through research", thus, contributing to a changing relationship between the university and research (McGregor \& Marker, 2018, p. 323).

To learn how to expose our students effectively to Indigenous knowledge, we looked to teacher educators and scholars engaging with Indigenous education within other Faculty of Education programs to explore effective sources and applications of Indigenous knowledge 
and ways of being. We have considered the possibilities for engaging Indigenous education with/in a higher education context, based on what has been learned from teacher educators with/in various other Faculties of Education, and extending this work in our space. In the post-secondary classroom, we engage with invited Indigenous scholars by positioning ourselves as co-learners with our students, while centering Indigenous voices and connecting with Indigenous people from the territory who guide and teach us. In this way, we aim first to demonstrate the need to engage with Indigenous perspectives in mainstream academia, and second to consider how to prepare non-Indigenous TCs to appreciate and respect traditional teachings.

\section{Weaving Indigenous Knowledge into the Curriculum}

Current practicing scholars (Davidson \& Davidson, 2018; Toulouse, 2018) highlight the importance of teacher educators beginning with Indigenous knowledge first, then making connections to the curriculum. We therefore address the hopes and fears around Indigenous Education by facilitating workshops wherein TCs can engage with Indigenous worldviews through an exploration of "storying", and connect these experiences to the Intermediate/Senior (I/S) English curriculum on multiple levels. Styres (2018) defines 'storying' as the "ways we describe, by means of stories, our experiences through personal, community, national, and global narratives to communicate not only among individuals but also between human beings and their world" (p. 25).

As teacher educators, we aim to prepare TCs to be culturally responsible by learning through relational education; that is, by "prioritizing Indigenous voices, incorporating Indigenous traditions in a respectful and appropriate way, acknowledging the historic and ongoing effects of colonization while also focusing on hope and demonstrating Indigenous people as survivors" (Brayboy \& Castagno, 2009, p. 32). Thus, by emphasizing first-person representations of Indigenous communities, culture, language, and Land (Dion, 2009; Kovach, 2009; Simpson, 2014), we can help move TCs out of epistemological complacency and into a supportive space of better, more informed relations with Indigenous peoples, so that their pedagogies begin to move accurately and respectfully towards an Indigenous focus.

\section{LITERATURE REVIEW}

Many Faculties of Education are committed to preparing pre-service teachers to implement Indigenous education programs (Madden, 2015). Madden (2015) encourages teacher educators to connect "pedagogical pathways" in charting their own route, taking into account their "unique place, positioning, talents, students, and priorities" (p. 13). She urges us to learn from these tracings and adapt examples that have been shared.

Our purpose is informed by the movement to include and prioritize culturally responsive pedagogies (Brayboy \& Castagno, 2009; Castagno \& Brayboy, 2008) as a method to transform the Eurocentric, middle-class cultural dominance of schooling by providing strategies and methods for incorporating pluralistic cultural pedagogies (Alim \& Paris, 2017). 


\section{Decolonization and Weaving Indigenous Knowledge}

Sanford et al. (2012) assert that applying Indigenous traditional models of teaching in teacher education represents a significantly different approach than the "colonizing model of teacher education" (p. 19) that operates through cognitive imperialism. "Cognitive imperialism' is defined as "the imposition of one worldview on a people who have an alternative worldview, with the implication that the imposed worldview is superior" (Battiste, 2000, p. 192-193). Madden (2015) suggests that when teacher educators are exposed to an Indigenous worldview, it "opens up space within the academy and schools to conceptualize education differently" (p. 4).

Our journey is reinforced by our responsibility as Settler teacher educators to appropriately prepare future Settler teachers for their role in the classroom, where they will be weaving Indigenous perspectives into their programs. Current literature states that we must begin deconstructing colonial constructs by acknowledging that everyone has been affected by colonialism (Pirbhai-Illich et al., 2017; Toulouse, 2016; Vowel, 2016). In a classroom setting, teaching about and learning how to challenge these constructs through inquiry provides opportunities to rethink and broaden resources, language, and pedagogy in course design (Toulouse, 2016).

In Madden's (2015) investigation, she outlines several studies (Brayboy \& Maughan, 2009; Dion, 2009; Sanford et al., 2012; Tanaka, 2009; Tanaka et al., 2007) which advocate for Indigenous Elders, knowledge holders, and artists to "facilitate co-learning that activates living Indigenous knowledges through traditional approaches" (p. 5). We believe it is our responsibility to work with Indigenous peoples from local communities to support learning in Indigenous and non-Indigenous education environments (Freeman et al., 2018; McGregor, 2012; Overmars, 2010). Current scholars doing this work, such as Scully (2020), suggest that Indigenous education in Canadian teacher education must center local Indigenous communities by "prioritizing relationships and learning contexts with them" (p. 227).

Several post-secondary institutions are demonstrating their commitment to taking up the "doubled task of modelling what it might mean to engage Indigenous education, while preparing teachers to carry on similar work differently in schools" (Madden, 2015, p. 13). Indeed, many Faculties of Education (Morcom \& Freeman 2018; Ng-A-Fook et al., 2017; Pratt et al., 2019; Scully, 2018; 2020; Styres, 2018) have introduced required or elective courses in Indigenous education in programs of formal teacher education which focus on diverse Indigenous Knowledges and pedagogies. These programs are creating a welcoming bridge between universities and Indigenous communities, opening space wherein experiences and perspectives interact.

We are also informed by current practicing scholars (Nardozi \& Restoule, 2015) who speak to educators seeking ways to enlighten teaching methodology while building relationships and opening pathways for Indigenous scholars, artists, and Elders to share their knowledge with their community. Recent publications have examined Indigenous perspectives being integrated in classrooms in ways that disrupt and decenter colonizing Eurocentric curricular discourses (Furo, 2018; Peters, 2018). Our research is mindful of the significant challenges 
that teachers may encounter when integrating Indigenous perspectives, particularly in schools that are made up of predominantly non-Indigenous teachers and students. It is welldocumented that many teachers struggle with teaching Indigenous perspectives (Dion et al., 2010), and lack both knowledge (Tupper, 2011) and resources (Dion et al., 2010; St. Denis, 2010). The literature outlining these challenges also reiterates that teachers continue to seek support in the form of teaching strategies and quality resources.

\section{Challenges to Integrating Indigenous Knowledge}

Capella-Santana (2003) argues that limited knowledge of Indigenous cultural backgrounds limits both a teacher's ability to teach this material as well as the overall academic experience afforded to Indigenous and/or non-Indigenous students. Several qualitative studies of teacher candidates found that integrating an Indigenous Knowledges perspective was complex (Kanu, 2007). Morcom and Freeman (2019) suggest that it takes the act of truly listening to Indigenous voices, in the effort to "find fitting paths forward" (para. 11), which involves "enacting the responsibility to promote right relations by widening the circle of learning and understanding" (para. 12).

Practicing scholars acknowledge the challenge of integrating Indigenous perspectives into the classroom curriculum and pose the question, "with whom?" (Furo, 2018, p. 13). The literature attests that this work must be done by building relationships (Brayboy \& Maughan, 2009). They suggest that "individuals live and enact their knowledge and, in the process, engage further in the process of coming to be - of forming a way of engaging others in the world" (Madden, 2015, pp. 4-5). This means re-evaluating knowledge systems and approaching these relationships with an ethics of respect and non-domination at the forefront (Donald, 2009; Ermine, 2007; Furo, 2018).

\section{Engaging with Indigenous Knowledge Keepers}

Madden (2015) suggests that although teacher educators may feel confident in their ability to teach TCs how to integrate Indigenous knowledges, perspectives, and pedagogical methods, they may not view themselves as "keepers of the knowledge" (p. 5), and thus appear to seek support in culturally appropriate and respectful ways. For example, being guided by an Elder from the community and/or inviting a Knowledge Keeper to teach about ways of knowing. Madden (2015) states, that most studies considered (Brayboy \& Maughan, 2009; Sanford et al., 2012; Tanaka, 2009; Tanaka et al., 2007), "relied heavily" (p. 4) on Indigenous Elders, knowledge holders, and artists to facilitate co-learning and investigation that activates living Indigenous knowledges through traditional approaches.

We are informed by several current teacher educators (Madden, 2015; Pete, 2016; Toulouse, 2016) engaging with Indigenous perspectives and knowledges to enable TCs and themselves to be enlightened by these perspectives. As teacher educators striving to prepare candidates to teach through culturally appropriate approaches, we have been situated "at the centre of negotiating the integration of Indigenous knowledges and pedagogical methods" (Madden 2015 , p. 2). Ma and Russel (2012) argue that both Indigenous and non-Indigenous teachers must see themselves as shifting education towards local Indigenous priorities, and situate teachers as having an understanding of "Indigenous education as a method", which includes 
"pedagogical approaches, curriculum developments and assessment issues around the learning needs of Indigenous students and how to teach non-Indigenous students about Indigenous society" (p. 20). Madden (2015) agrees, that "Faculties of Education are fertile ground for exploring sources of knowledge and methods of knowing about Indigenous education" (p. 2).

Our approach is reflective of one of Madden's (2015) "pedagogical pathways": "Learning from Indigenous traditional models of teaching" (p. 2). Madden outlines that universitybased Indigenous programs (Williams, 2006) are engaging teachers in "demonstrat[ing] possibilities for teacher education, and by extension schooling for Indigenous students, that emerge when courses are structured to provide teachers the opportunity to experience firsthand how teaching and learning occur in an Indigenous world" (as cited by Tanaka, 2009 , p. 19). Madden explains that this pathway is grounded in what has been referred to as "traditional knowledge, oral knowledge, [and] Indigenous knowledge" (Kirkness \& Barnhardt, 1991, p. 4). Madden also reminds us of Battiste and Youngblood Henderson's (2000) assertion that Indigenous knowledge "is not a uniform concept across Indigenous peoples" (p. 35).

Working together with Indigenous speakers to share their stories and experiences is one way to engage future educators in developing awareness, appreciation and understanding of Indigenous peoples (Mashford-Pringle \& Nardozi, 2013). But, it is also to ensure the acknowledgement of Indigenous knowledge as highly valuable and relevant, and to be able to be woven with knowledge used in Western education.

\section{RESEARCH DESIGN AND METHODOlOGY}

This study was grounded in Action Research, which begins by "considering the processes and relationships that make up what we think of as a [teaching] practice, which includes its history and possible futures" (Ross, 2020, pp. 20-21). Inquiries into these practices help us understand how things change and also contribute to change. We also consider this research as a "commitment to bring together broad social analysis, the self-reflective collective selfstudy of practice, and transformation action to improve things" (Kemmis et al, 2014, p. 12). Narrative inquiry was helpful in revealing, understanding, and reflecting on our own process of AR. The current study is burgeoning upon a participatory action research methodology (PAR), wherein the Indigenous presenters would have a larger role to play in all aspects of the research, including choosing the questions and being involved in analysis. Caxaj (2015) suggests that narrative and PAR approaches, guided by Indigenous knowledge, have great potential to build methodologically and ethically robust research. Shaped by local Indigenous ways of knowing, our research was intended to build a foundational relationship resulting in future projects reflective of ongoing relationality, and ultimately to effect change in our institutional practices.

\section{Our Approach}

This action research study was built upon the foundation of relationships with the Indigenous invitees, and with our growing understanding of Indigenous epistemology and methodologies about which we, as co-learners, are beginning to understand more fully 
through listening to and becoming informed by current Indigenous scholars. What we hoped to gain from the present study was to figure out what additional supports might be needed for TCs to engage in Indigenous Education, and to model relationship-building and collaboration with Indigenous educators, Knowledge Keepers, and storytellers in working towards a shared vision of what these and future workshops achieve.

We developed relationships with presenters in order to formulate a collective approach to our research. Our process unfolded in the following steps:

1. We reached out to Indigenous educators, Knowledge Keepers, and storytellers living and working within the Ontario Education system on Treaty 13 Territory. Carol conceptualized the idea to facilitate an Indigenous Education platform as a conference at another institution in the spring of 2015. In preparing for that conference, Carol met Indigenous community members who guided her in finding a space, a time, and funding for the conference, and also in the protocols of working together. One particularly fruitful collaboration occurred with Carol's former grade 8 teacher, Robert Cutting, himself of Kanienkeha'ka ancestry, which resulted in their bringing Indigenous storytelling and pedagogies into the classrooms of TCs. Having shifted to a new institution of higher learning, Carol continues to learn and build relationships with others who share her interest in bringing Indigenous Education to the forefront of Education in Ontario, and to future teachers in our schools.

2. Key to our action research was that the initial action (i.e. our initial conferencing and coordinating with Indigenous presenters) generated insights and questions for us that would point to further action of the inclusion (and centering) of Indigenous perspectives in our teacher education program. The learning we gained from that experience included sharing our aim for the Indigenous Education conference with presenters. Our institution is a bi-national university with a focus on social justice and local and global community building. Our teacher education program is 2-years in length, including methods courses for primary/junior and intermediate/senior divisions, but there is no dedicated Indigenous Education course. Therefore, beginning in 2018, Carol facilitated the inaugural one-day Indigenous Education Conference which became an annual series of workshops over three weeks in 2020. This one-day Indigenous Education Conference included Traditional Opening and Closing ceremonies, a local educator and storyteller, Robert Cutting (Kanienkeha'ka), to deliver the plenary remarks, followed by interactive workshops. The workshops integrated Indigenous storytelling, lived experiences of Traditional Knowledge Keeper, Diane Montreuil (Métis), and Indigenous scholar, Marina Ford (Shoshone/Cherokee). The process that led to the present series of workshops conference emerged when TCs began asking first, how they could authentically engage their First Nations, Métis, and Inuit students to understand more about Indigenous education and culture, and second, how they themselves could become more inclusive teachers. To broaden opportunities for TCs' understanding of diverse narratives and teachings within Indigenous Knowledge, the Indigenous Education workshops align with Ontario Ministry of Education strategies and help implement the Calls to Action (TRC, 2015a): Call to Action 62 requires the integration of knowledge on Indigenous historical and contemporary issues, as well as the development of curriculum in primary and secondary education; Call to Action 63 requires the development of teaching 
and learning tools for "building student capacity for intercultural understanding, empathy, and mutual respect" (p. 7) through the development of curriculum, integration of content, and training of teachers to advance awareness of the history and legacy of residential schools.

Originally created as a full-day conference, Carol now facilitates a dedicated Indigenous Education workshop series for the Year 2 teacher candidates. This series of workshops on Indigenous Education provides a variety of learning opportunities for TCs and was created with input from First Nations storytellers and authors, Indigenous Elders and traditional Knowledge Keepers, Métis artist and entrepreneur, Diane Montreuil, and local School Board Consultants and Educators of Indigenous Programs. Over three weeks at the beginning of Term 2, eight workshops were created where teacher candidates had a choice of three sessions. Workshop leaders were invited to share their knowledge by following the appropriate protocols, such as a traditional Land Acknowledgement and Sharing Circles. Separate classrooms were utilized and organized per the requests of the workshop leaders (for example, to include teaching circles).

The methodologies, tools, and approaches used in the workshops varied with each presenter and in different contexts. Each guest came with their own traditional knowledge and lived experience, and shared them through storytelling, artwork, and ceremony. Therefore, this action research did not focus on one specific Indigenous methodology; rather, it took a broad look at the effect that the information and traditional knowledge had on participants, ranging from emotional impact to a clearer understanding of Indigenous histories, cultures, and knowledge systems.

3. We worked together to address Settler TC needs and ensure a comfortable learning environment for speakers and audience members. Laryssa, the first author, worked closely with workshop presenters, collaboratively developed survey questions to gauge the needs of TCs, and discussed the diversity of topics which might be addressed in the presentations. Laryssa helped to coordinate a workshop slideshow for Métis Knowledge Keeper, Diane Montreuil, with whom she presented. Furthermore, Laryssa coordinated a virtual presentation facilitated by Shoshonee and Cherokee scholar, Marina Ford, for her EDU 461 Methods course, a course designed to explore pedagogies and practice from diverse perspectives.

\section{Ensuring Cultural Sensitivity}

We wanted to ensure that we followed proper protocol when inviting our presenters to speak at our conference. As suggested in Madden's research (2015), we made it our priority to express respect, responsibility, and appreciation for knowledges shared. Carol applied and obtained internal university grants, plus funding from the College of Education, to provide honorariums, meals, and other funding for the workshop leaders. Over the years, both authors developed friendships through learning to hold space for Indigenous voices. We were honest about our own lack of authentic knowledge of diverse Indigenous lived experiences, and learned to take time to listen to our partners, and hold their stories at the forefront of curriculum. We are honoured to continue sharing space with these individuals 
from whose experiences we learn and grow, and who bravely create welcoming environments for challenging and trauma-informed conversations.

During the past year, we have continued our learning in collaboration with Indigenous partners and invite our TCs to journey with us as we grow in understanding. We hope to continue our relationships and ground our work in a more participatory fashion moving forward, wherein the needs of the local Indigenous community members are given prominence, and that the research could help them meet those needs.

\section{Participants}

Since the purpose of AR is to inform future action, we conducted our research on our teacher candidates' work and perspectives. Ultimately, we wanted to understand the impact Indigenous guest speakers and workshop leaders might have on helping settler-teacher candidates navigate Indigenous content in culturally appropriate and respectful ways. We utilized feedback survey questionnaires through google forms and left space within the documents for open-ended comments (See Appendices 1 and 2), and option for reflection (Appendix 4) from teacher candidates' (focus group) coursework.

Our research follows two groups:

1. Year 2 teacher candidates who are non-Indigenous in the Primary/Junior (P/J) and Intermediate/Senior (I/S) cohorts, plus a smaller group of Year 1 teacher candidates in the I/S cohort. While approximately 100 teacher candidates had access to the workshops, 24 completed the Google feedback form.

2. A small focus group of pre-service Year One teacher candidates taking the I/S English Methods course who wished to gain an understanding of how to weave Indigenous knowledge and perspectives into their lesson planning. When they enter into the profession, and/or work with the revised Canadian and World Studies Grades curriculum in place in intermediate classrooms, these I/S students will more than likely have opportunities to teach the compulsory Grade 11 English course offered in most Ontario secondary schools titled, English: Understanding Contemporary First Nations, Métis and Inuit Voices, a course designed to honour Indigenous voices. For this study, approximately 8 students from I/S English Methods course were surveyed (See Appendix 2) and observed as they participated in workshops with a Métis Knowledge Keeper, Diane Montreuil, and a First Nations scholar, Marina Ford (Shoshone \& Cherokee Nations). Six TC's completed the form. Students were already familiar with Indigenous histories, identities and (some) cultural ways of knowing. This prior knowledge allowed for an initial data point to then analyze how the application of their knowledge (for the purpose of lesson planning) was made more meaningful and engaging throughout the learning experience.

\section{RESULTS}

\section{Ratings of Workshops}

100 TCs were asked to complete a questionnaire with some short answer responses (see Appendix 1) at the end of the workshops, of whom 24 responded. Some participants 
answered in multiple ways, so we collated their responses in graphic form (figure 1), wherein the vertical axis represents the number of responses referring to each topic (as seen on the horizontal axis).

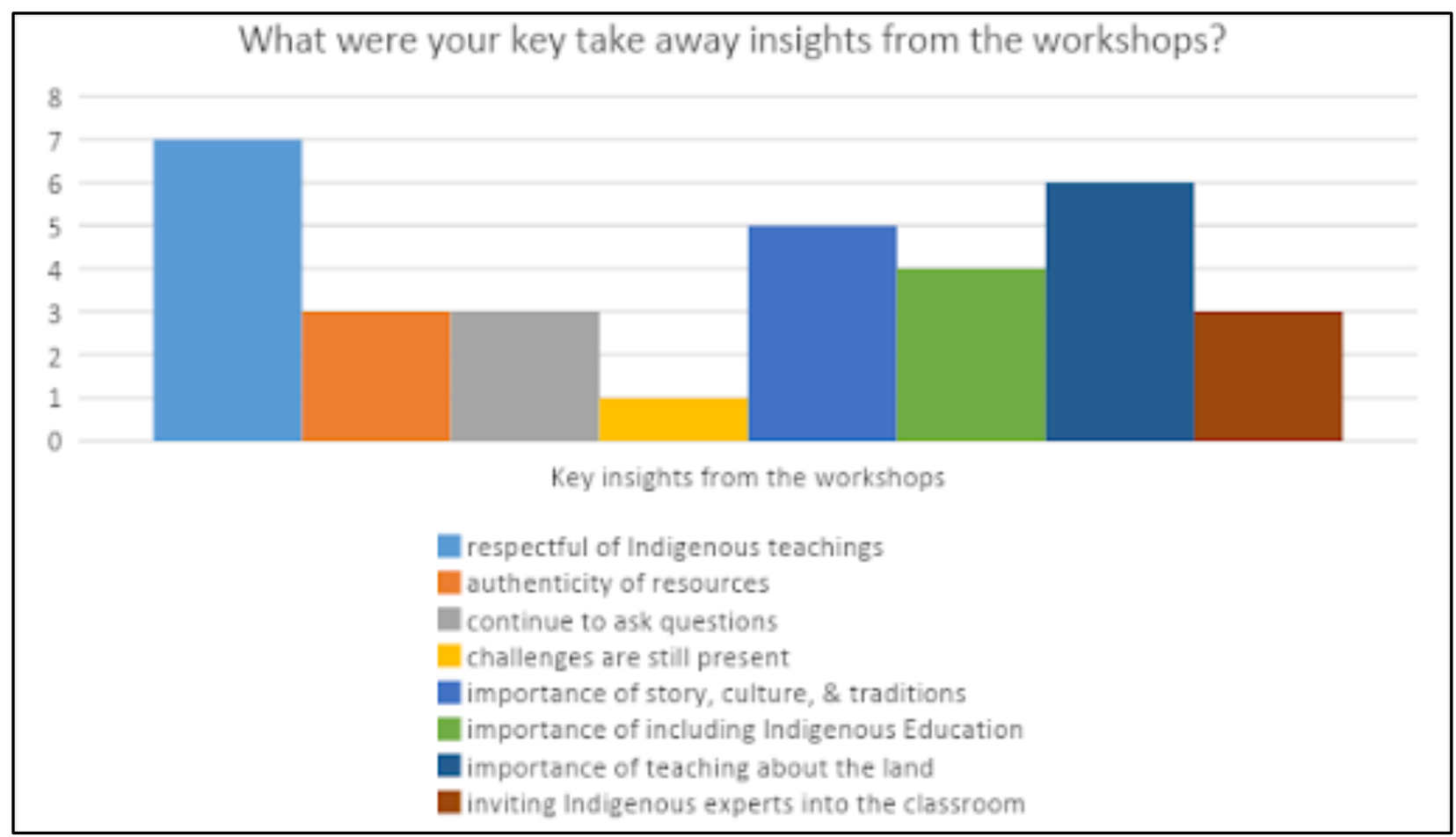

Figure 1. Key insights from the workshops

Figure 2 depicts TC ratings of how well the workshop series broadened their understanding of Indigenous perspectives.

To what degree did the workshop series broaden your understandings of Indigenous perspectives?

24 responses

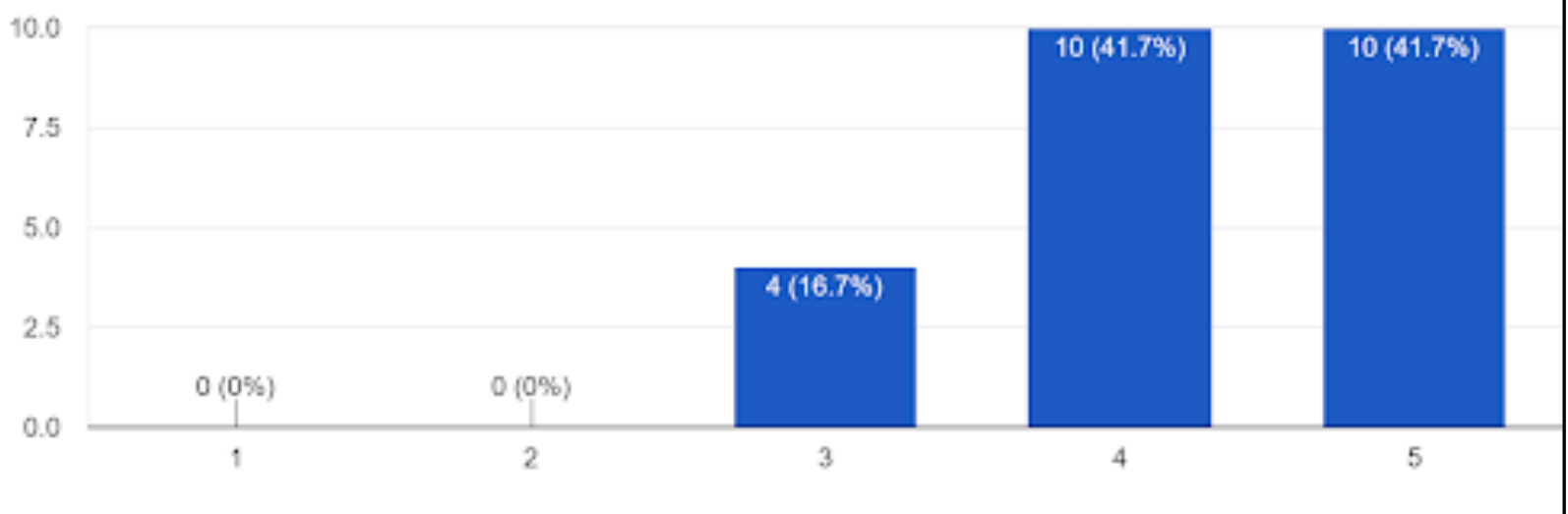

Figure 2. Understandings of Indigenous perspectives

The Canadian Journal of Action Research, Volume 21, Issue 3 (2021), 115-141 
Furthermore, seven TCs from the focus group were asked to complete a questionnaire (see Appendix 2) at the end of the virtual presentation, and 6 responded. We asked them to rate how well the workshop series broadened their understanding of Indigenous perspectives. Some results for this questionnaire are reported in figure 3 and figure 4.

\section{To what degree has this presentation broadened your understanding of Indigenous perspectives? \\ 6 responses}

3

西

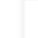

2

1

\section{$1(16.7 \%)$}

0

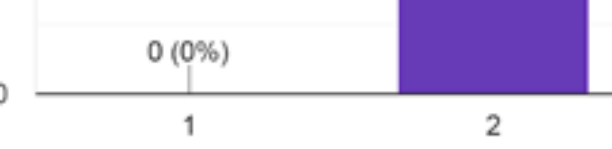

Figure 3. Understandings of Indigenous perspectives from focus group

To what degree has your comfort level with teaching Indigenous perspectives in your future classrooms improved?

6 responses

3

$+$

2

1

0
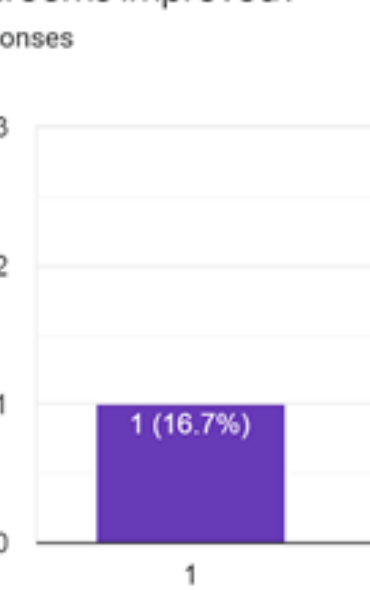

\section{$2(33.3 \%)$}
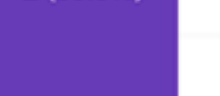
understand. One TC shared: "I need more help with this. I am still gathering these pieces." Another expressed the importance of being honest and acknowledging the challenges they would encounter as educators. Nevertheless, the TCs found that the workshops and presenters were very helpful in their emerging curriculum planning and teaching, and recognized that this is just one step on a long journey. The voices - past and present - of Indigenous peoples are essential in developing culturally relevant, sensitive, and responsive pedagogy.

Most TCs wanted to know more about all topics, but 12 (50\%) thought that the TRC Calls to Action about reconciliation and land-based teaching would be the most challenging, followed by integrating contemporary Indigenous perspectives and the effects of colonialism. Only one TC felt sufficiently prepared to begin teaching aspects of Indigenous education in a classroom.

From experiences that took place prior to the workshop to when they provided feedback on their understandings, the majority of the TCs found ways to engage with the information and the presenters. One TC shared that "inviting Indigenous representatives to the classroom is imperative for reconciliation, rebuilding and educating future generations." Moreover, "truly understanding Indigenous culture - speaking directly to the source, even if it makes you uncomfortable. That is how we pay respect - it is not about just reading an Indigenous book to the class."

Another TC went a step further in her reflection and shared that she was interested in "learning about how to get the class involved in initiatives that support Indigenous peoples." Furthermore, she asked: "What can we, as a class, do besides educate ourselves on Indigenous Education that will allow us to be better allies?" She also expressed a desire for resources and practices that would help to "debunk stereotypes and open our eyes to the reality of what is going on in Canada."

We were working to disrupt settler teacher perceptions explicitly from the conference presentations and activities in Indigenous-focused contexts, and were prepared for some discomfort, tensions, and complexities. Not surprisingly, some TCs were occasionally dissatisfied with our attempts to introduce Indigenous collaborators. For example, in Laryssa's English Methods course, which was taught from a western teaching approach, after a virtual presentation by an invited Indigenous scholar who spoke on subjects such as spirituality and cultural appropriation, one of the TCs in the focus group reflected:

If you want my honest opinion I learned more from your teaching [i.e. from a western perspective], the books we've read, and past speakers [from the conference] than this presentation... I understand that this cannot be done over conferences, however I did not find this particular presentation very helpful. I don't think I learned anything new and the answer to a question I asked, got me more confused than I was before I asked it. 
Indeed, hearing about lived experiences from authentic voices might cause some discomfort for TCs since the sharing of these experiences is individual and organic, and not linear as in many Western approaches to learning.

Finding authentic and engaging resources is a key part of what TCs expect when they participate in workshops. Resources can come in different formats, and that is what the TCs uncovered as they provided feedback on the sessions. In their post-surveys, they stated that "having speakers come in, schools encouraging learning of Indigenous education, having open access and being shown where to find good resources" is meaningful for future teachers. The TCs also found ways to "ensure that [their] Indigenous resources and lessons are authentic" by engaging in conversation with the workshop leaders. Some examples included integrating Indigenous art, history, and stories. Learning about different school board- and community-based programs were also key learning opportunities during the workshops. One TC revealed that they continue to have questions: "How we can feel more confident implementing this topic, and asking questions. Always, it's okay to ask!"

\section{IMPLICATIONS FOR ONGOING PRACTICE}

This research project taught us about what we might do better or differently when it comes to meaningful engagement of Teacher Candidates preparing to teach and learn about Indigenous Education. Data collected were synthesized to craft recommendations about improving the Teacher Education program so that the courses therein contain appropriate, accurate, and authentic Indigenous content in the future and share best practices on teaching curriculum related to the TRC Calls to Action (2015). The goal was also to help teachers embrace more Indigenous-respectful pedagogies and to observe how this is done in/through relationships with Indigenous peoples. The main themes that emerged from the data include: developing new perspectives, the gift of storytelling, the value of hands-on experiences, and meaningful curriculum applications.

\section{Developing New Perspectives of Traditional \& Cultural Knowledge}

The workshops presented the TCs with diverse speakers, views, and stories, providing opportunities to broaden their own perspectives. The majority of the TCs, prior to the conference, felt that while they had some knowledge about such topics as residential schools, they still had so much to learn about Indigenous education.

TCs particularly appreciated the "real life experiences told" during the workshops. They mentioned in their survey responses that they were grateful to "understand personal narratives and backgrounds of each teacher/speaker." TCs felt that they were gaining important knowledge about the "history of Indigenous communities and gaining more appreciation for traditions." These understandings included glimpsing "how ceremonies take place and forms of acknowledgement about symbols and traditions." For instance, "teaching about how the land and [we] ourselves are connected and that we should be teaching students to respect the land using various techniques/using Indigenous teaching language." This is a significant AR finding, as it suggests that we discuss with the presenters and other Indigenous colleagues how land, in particular the grounding of learning interactions in relation to land as first teacher (Syres, 2011), as well as language, might be 
foregrounded more in the future workshop experience. Most notably, TCs made connections between Indigenous peoples and their own lives, building capacity to authentically and respectfully integrate knowledge, while continuing to pose insightful questions.

\section{The Gift of Storytelling}

Through this project, strong themes emerged out of the TCs' desire to understand and integrate Indigenous education authentically and respectfully. One element that resonated with the TCs was storytelling. As some of the presenters integrated storytelling, or "the conversational method" (Kovach, 2010) in their workshops, many of the TCs found this method of "teaching through story" to be a meaningful way of sharing knowledge. Indeed, Carol noted that more TCs are sharing stories and narratives authored by Indigenous storytellers both in their literacy-based projects and during their field placements after engaging with Robert Cutting's workshop, Gift of Story. This implies that developing storytelling skills and incorporating them in the teacher education program would be beneficial.

\section{The Value of Hands-On Experiences}

During the various workshops, hands-on experiences were often integrated. TC's stated that the hands-on practices and discussions provided them with "the ability to have a space to listen, learn and practice, help promote, and provide confidence for [their] future lessons." For example, interactions were provided through Diane Montreuil's textile workshop, and through witnessing the pedagogical process in accordance with local protocols. TCs were particularly engrossed in how the hands-on work they were participating in created further connections to Diane's Métis lived experience and connection to the Land and its teachings. Based on another workshop, another TC shared how seeing the presenter's "artifacts and passing them around whilst learning the history behind them" was an incredibly powerful experience.

One of the TCs shared how she participated in a work-study program in Aamjiwnaang near Sarnia. During her stay, she experienced hands-on language, art, dance, and ceremonies classes. This TC already understood the importance of expert teachers, including students, in the school as she learned that teachers were not the only experts in the classroom: "students teaching me about their traditions and dances" was a key facet of her own learning as a teacher. As another TC noted: "Direct participation is key to understanding more about Indigenous peoples and traditions." This finding has reinforced our efforts for future programming to include experiential learning led by Elders and Knowledge Keepers.

\section{Meaningful Curriculum Applications}

Prior to the Indigenous-focused mini-lesson assigned to the focus group participants in the EDU methods course, data show that TCs, albeit familiar with Indigenous content, were still hesitant about weaving it authentically into their lessons (See Appendix 3 for prepresentation survey, and Appendix 4 for TC reflection questions). Amelia attested: "I wasn't very comfortable with the idea of teaching Indigenous content, because I felt as though I didn't have enough education in it/experience with it." Amelia designed an Indigenous education unit that reflected her individual identity, social location, and her privilege. She 
acknowledged the necessity that the Indigenous perspective should be taught through "actual" Indigenous voices, and that there are "different Indigenous perspectives". TCs were offered a plethora of Indigenous-authored texts, in addition to the narratives and perspectives listened to at the workshops, around which to build their lesson. Amelia commented that

the resources provided to me helped me become more confident with the content and throughout the semester. I was encouraged to tackle this subject because I realized that the important part is that, as a non-Indigenous person, I put all of my efforts into finding reliable/authentic resources that provide a non-biased perspective on the effects of colonization. As long as I did this, I was being respectful towards the culture.

This data suggests that TCs went from feeling uncomfortable to comfortable in curriculum planning. We clarify here, however, that comfort does not imply complacency. Results indicated the TC's are even more inspired and motivated to learn what weaving Indigenous perspectives into their practice might look like for them, with a focus on building relationships with Indigenous peoples and inviting them to share their knowledge in their classrooms. Because this mini-lesson activity was assigned as a way to work through her own understandings about authentic resources and perspectives, Amelia recognized the fluidity and organic nature of curricula. Amelia decided to do her culminating unit plan on the English: Understanding Contemporary First Nations, Métis and Inuit Voices NBE3C course. Her final reflection was:

I wanted to further my experience in researching and developing lessons based on Indigenous content... I chose to plan a unit for this course because it took me out of my comfort zone, but I felt prepared enough to tackle it because of the informative presentations we've had throughout the semester. Since my chosen subject is the Understanding Contemporary First Nations, Métis and Inuit Voices course, I had to create lessons to teach students the importance of community, inclusion, respect, and reconciliation. In order to provide my students with legitimate, truthful facts, I found it very important to include texts that are written by an Indigenous person. This is how I plan to teach the effects of colonization on Indigenous communities, because I do not want to formulate bias for my students or myself.

We believe this is of utmost importance - that Amelia is reinforcing the evolution of her teaching and learning identity (Phillips et al., 2007).

\section{Conclusion ANd NeXt STEPS}

As research-practitioners, we are learning more about effective avenues for including Indigenous pedagogies into our programming. Our story serves as one possible approach to learning in relationship with Indigenous peoples, as it describes cycles of inquiry regarding respectfully putting Indigenous voices at the center in the context of Indigenous Education 
at the post-secondary level. We hope others will take away whatever is useful to them on their pedagogical journeys.

We hope our work might link to Madden's (2015) "pathway circle," knowing that some elements therein might remain constant while others fluctuate, and the journey is "continuously contextual, distinct, relational, and unforeseeable" (p. 3). We remain supportive of and committed to demonstrating that Settler TCs can enact positive influence in our community, which can likely lead to subsequently building stronger genuine relationships with Indigenous communities, and, in turn, improving learning conditions for their future students. Learning from Indigenous traditional models of teaching upholds the holistic and relational characteristics of Indigenous knowledges (Madden, 2015). However, we are aware that "unexpected contexts and needs may arise in the future as pedagogy produces, and thus, teacher educators could remain on the lookout for occasions to temporarily journey on other pathways" (p. 8).

Our project seeks to acknowledge the pedagogical challenges that non-Indigenous TCs struggle with, and to build promising practices that better prepare them. We seek pedagogical approaches that center Indigenous perspectives in learning, and actively work to build a new relationship between Indigenous and non-Indigenous peoples based on an ethics of respect, equality, and inclusion.

We agree with McGregor and Marker (2018), that reciprocity is a "journey". We view this project not as a "fixed point on a map" (p. 325), but rather, we are actively designing future research projects in collaboration with Indigenous colleagues as part of a broader movement towards decolonizing, which includes "a willingness to contribute to changing what it means to participate in the university and in research altogether" (p. 323).

We are moving towards PAR as we become more informed and continue to build relationships. We are committed to continuing the partnerships even after the research has concluded. For example, as an extension to this project, we are planning for future involvement of, and contributions by, these - and other - Indigenous presenters to assist in co-teaching of Indigenous knowledges. Through this approach, the process of knowledge creation can shift away from the mainstream and instead articulate a knowing that reflects Indigenous lives and values (Bartlett et al., 2007). Indeed, our Indigenous colleagues have many connections to community members whom we would invite to be a part of this work (for future conferences and possible speaking engagements with our community), and we welcome this space for dialogue.

We are dedicated to continuing the Indigenous Education conference and workshops annually at our institution, and to broadening the scope of it to include even more Indigenous contributors and/or community members. We plan to take an active role in continuing to engage in Indigenous education with/in our Faculties of Education through this and other holistic approaches, which might eventually lead to a 'stand-alone' course in our institution. We hope our action research will serve as one possible direction in continuing to inform ourselves and others on how relationships produced within the context of Indigenous ways 
of knowing are centered. As such, we hope to take on a PAR framework in the future. Furthermore, through our relationships with Indigenous scholars, Elders, and partners, we might begin to design a course reflective of Indigenous epistemologies. Pete (2015) states that "Aboriginal programs should to some degree reflect approaches to epistemology preferred by Aboriginal persons and encouraged by Aboriginal cultural traditions, [...] values and ways of being" (p. 7).

Through the examination of including Indigenous perspectives through action research, we hope to advance research that upholds Indigenous voices and experiences that have remained marginalized. It is also an opportunity for faculty, students, and Indigenous communities to learn and grow together in a better direction; one that inspires knowledge production and dissemination within schools, colleges and universities; one that invites perspectives to be shared through dialogue and epistemological pluralism; and one that provokes change.

\section{GRATITUDE}

A special thank you to Robert Cutting for his advice, guidance, and teachings, his Gift of Story during this project, to Métis artist and Knowledge Keeper, Diane Montreuil, who helped us conceptually represent the insights we gained through her artwork, and to Marina Ford, who so graciously shared her scholarship and experiences. We would also like to thank the participants interviewed for sharing their valuable knowledge and experience.

\section{REFERENCES}

Alim, H. S., \& Paris, D. (2017). What is culturally sustaining pedagogy and why does it matter. In H. S. Paris \& D. Alim (Eds.), Culturally sustaining pedagogies: Teaching and learning for justice in a changing world (pp. 1-24). Routledge.

Archibald, J. (2008). Indigenous storywork: Educating the heart, mind, body and spirit. UBC Press.

Bartlett, J. G., Iwasaki, Y., Gottlieb, B., Hall, D., \& Mannell, R. (2007). Framework for Aboriginal-guided decolonizing research involving Métis and First Nations persons with diabetes. Social Science \& Medicine, 65(11), 2371-2382. https://doi.org/10.1016/j.socscimed.2007.06.011

Battiste, M. (2013). Decolonizing education: Nourishing the learning spirit. Purich Publishing.

Battiste, M. (2005). Indigenous Knowledge: Foundations for First Nations. WINHEC: International Journal of Indigenous Education Scholarship, (1), 1-17.

Battiste, M. (2000). Maintaining Aboriginal identity, language, and culture in modern society. In M. Battiste (Ed.), Reclaiming Indigenous voice and vision (pp. 192-208). UBC Press.

Battiste, M., \& Youngblood Henderson, J. (2000). Protecting Indigenous knowledge and heritage: A global challenge. UBC Press. 
Bell, N., \& Brant, T. (2015). Culturally relevant Aboriginal education. Pearson.

Brayboy, B. M. J., \& Castagno, A. E. (2009). Self-determination through self-education: Culturally responsive schooling for Indigenous students in the USA. Teaching Education, 20(1), 31-53. https://doi.org/10.1080/10476210802681709

Brayboy, B. M. J., \& Maughan, E. (2009). Indigenous epistemologies and teacher education: The story of the bean. Harvard Educational Review, 79(1), 1-21. https://doi.org/10.17763/haer.79.1.10u6435086352229

Capella-Santana, N. (2003). Voices of teacher candidates: Positive changes in multicultural attitudes and knowledge. The Journal of Educational Research, 96(3), 182-190. https://doi.org/10.1080/00220670309598806

Castagno, A. E., \& Brayboy, B. M. J. (2008). Culturally responsive schooling for Indigenous youth: A review of the literature. Review of Educational Research, 78(4), 941-993.

Caxaj, C. S. (2015). Indigenous storytelling and participatory action research: Allies toward decolonization? Reflections from the peoples' international health tribunal.

Davidson, S. F. \& Davidson, R. (2018). Potlatch as Pedagogy: Learning through Ceremony. Portage and Main Press.

Dion, S. D. (2009). Braiding histories: Learning from Aboriginal peoples' experiences and perspectives. UBC Press.

Dion, S. D., Johnston, K., \& Rice, C. (2010). Decolonizing our schools: Aboriginal education in the Toronto District School Board. https://www.tdsb.on.ca/Portals/0/Commun ity/docs/Decolonizing\%200ur\%20Schools\%203.pdf

Donald, D. (2009). Forts, curriculum, and Indigenous Métissage: Imagining decolonization of Aboriginal-Canadian relations in educational contexts. First Nations Perspectives, 2(1), 1 24. https://doi.org/10.1080/09518398.2011.554449

Ermine, W. (2007). The ethical space of engagement. Indigenous Law Journal, 6(1), 193. https://jps.library.utoronto.ca/index.php/ilj/article/view/27669

Freeman, L. A., \& Staley, B. (2018). The positioning of Aboriginal students and their languages within Australia's education system: A human rights perspective. International Journal of Speech-Language Pathology, 20(1), 174-181. https://doi.org /10.1080/17549507.2018.1406003 
Furo, A. (2018). Decolonizing the classroom curriculum: Indigenous knowledges, colonizing logics, and ethical spaces [Doctoral dissertation, Université d'Ottawa/University of Ottawa]. http://hdl.handle.net/10393/37106

Kanu, Y. (2011). Integrating Aboriginal perspectives into the school curriculum: Purposes, possibilities, and challenges. University of Toronto Press.

Kanu, Y. (2007). Increasing school success among Aboriginal students: Culturally responsive curriculum or macrostructural variables affecting schooling? Diaspora, Indigenous, and Minority Education, 1(1), 21-41. http://doi.org/10.1080/15595690709336599

Kemmis, S. (2014). Introducing critical participatory action research. In S. Kemmis, R. McTaggart, \& R. Nixon (Eds.), The action research planner: Doing critical participatory action research (pp. 1-31). Springer.

Kirkness, V. J., \& Barnhardt, R. (1991). First Nations and higher education: The four R'srespect, relevance, reciprocity, responsibility. Journal of American Indian Education, $1-15$.

Kovach, M. (2010). Conversation method in Indigenous research. First Peoples Child \& Family Review, 5(1), 40-48.

Kovach, M. (2009). Indigenous methodologies: Characteristics, conversations and contexts. University of Toronto Press.

Kuokkanen, R. (2011). Reshaping the university: Responsibility, Indigenous epistemes, and the logic of the gift. UBC Press.

Ma Rhea, R. \& Russel, L. (2012). The invisible hand of pedagogy in Australian Indigenous studies and Indigenous education. The Australian Journal of Indigenous Education, 41(1), 18-25. https://doi.org/10.1017/jie.2012.4

Madden, B. (2015). Pedagogical pathways for Indigenous education with/in teacher education. Teaching and Teacher Education, 51, 1-15.

Mashford-Pringle, A., \& Nardozi, A. G. (2013). Aboriginal knowledge infusion in Initial Teacher Education at the Ontario Institute for Studies in Education at the University of Toronto. The International Indigenous Policy Journal, 4(4). https://doi.org/10.18584/iipj.2013.4.4.3

McGregor, H. E. \& Marker, M. (2018). Reciprocity in Indigenous educational research: Beyond compensation, towards decolonizing. Anthropology \& Education Quarterly, 49(3), 318-328. https://doi.org/10.1111/aeq.12249 
McGregor, H. E. (2012). Decolonizing pedagogies teacher reference booklet. Aboriginal Focus School, Vancouver School Board. http://blogs.ubc.ca/edst591/files/2012/03/ Decolonizing_Pedagogies_Booklet.pdf

Morcom, L. \& Freeman, K (2019). Teaching truth and reconciliation in Canada. Queen's Gazette. https://www.queensu.ca/gazette/stories/teaching-truth-and-reconciliat ion-canada

Morcom, L., \& Freeman, K. (2018). Niinwi-Kiinwa-Kiinwi: Building non-Indigenous allies in education through Indigenous pedagogy. Canadian Journal of Education/ Revue canadienne de l'éducation, 41(3), 808-833.

Nardozi, A., \& Mashford-Pringle, A. (2014). Engaging teacher candidates about Aboriginal education perspectives in Ontario. First Nations Perspectives, 6(1), 52-66.

Nardozi, A., \& Restoule, J. P. (2020, May 6). What does decolonization and Indigenization look like in the classroom? [Webinar] https://www.angelanardozi.com/webinars

Nardozi, A., Restoule, J. P., Broad, K., Steele, N., \& James, U. (2014). Deepening knowledge to inspire action: Including Aboriginal perspectives in teaching practice. In Education, $19(3)$.

Ng-A-Fook, N., Kane, R., Crowe, T., Karagiozis, N., \& Hagerman, M. S. (2017). Reconceptualizing teacher education at the University of Ottawa. In D. Petrarca \& J. Kitchen (Eds.), Initial teacher education in Ontario (pp. 217-242). Canadian Association for Teacher Education.

Ontario Ministry of Education's Approach to Indigenous Education. (2020). https://www.nccie.ca/story/ontario-ministry-of-educations-approach-to-indigenou s-education/

Overmars, D. (2010). Indigenous knowledge, community and education in a western system: An integrative approach. First Peoples Child \& Family Review: An Interdisciplinary Journal Honouring the Voices, Perspectives, and Knowledges of First Peoples through Research, Critical Analyses, Stories, Standpoints and Media Reviews, 5(2), 88-95.

Pete, S. (2016). 100 Ways: Indigenizing \& decolonizing academic programs. Aboriginal Policy Studies, 6(1). 81-89. https://doi.org/10.5663/aps.v6i1.27455

Pete, S. (2015). 100 ways to Indigenize and decolonize academic programs and courses. University of Regina. https://towards-indigenizing.trubox.ca/wp-content/uploads/ sites/237/2017/01/100-ways-to-indigenize.pdf 
Peters, K. (2018). Inclusion of Indigenous education: Examining pre-service teachers' knowledge and attitudes towards the integration of Indigenous education [Doctoral dissertation, Queen's University]. http://hdl.handle.net/1974/24420

Phillips, S., Phillips, J., Whatman, S., \& McLaughlin, J. (2007). Introduction: Issues in (re)contesting Indigenous knowledges and Indigenous studies. The Australian Journal of Indigenous Education, 36 (1), 1-6. https://doi.org/10.1017/S1326011100004634

Pirbhai-Illich, F., Pete, S., \& Martin, F. (Eds.). (2017). Culturally responsive pedagogy: Working towards decolonization, indigeneity and interculturalism. Springer.

Poitras Pratt, Y., \& Hanson, A. J. (2020). Indigenous instructors' perspectives on pre-service teacher education: Poetic responses to difficult learning and teaching. Race Ethnicity and Education, 1-19. https://doi.org/10.1080/13613324.2020.1718085

Pratt, Y. P., Danyluk, P., Beech, S., Charlebois, S., Evans, C., Fehr, A., Nielsen, A., \& Sanregret, A. (2019). Pathfinders: Realizing reconciliation through lessons learned. Papers on Postsecondary Learning and Teaching, 3, 95-102.

Ross, E. W. (2020). Why are things as they are? Action research a transformation of work and education in the neoliberal age. The Canadian Journal of Action Research, 21(1), 10 26. https://doi.org/10.33524/cjar.v21i1.515

Sanford, K., Williams, L., Hopper, T., \& McGregor, C. (2012). Indigenous principles decolonizing teacher education: What we have learned. In Education, 18(2). https://journals.uregina.ca/ineducation/article/view/61

Scully, A. (2020). Land and critical place-based education in Canadian teacher preparation: Complementary pedagogies for complex futures. In M. Corbett \& D. Gereluk (Eds.), Rural Teacher Education: Connecting Land and People (pp. 227-244). Springer.

Scully, A. J. (2018). Whiteness and land in Indigenous education in Canadian teacher education [Unpublished doctoral dissertation]. Lakehead University.

Simpson, L. B. (2014). Land as pedagogy: Nishnaabeg intelligence and rebellious transformation. Decolonization: Indigeneity, Education \& Society, 3(3), 1-25.

Snowball, A. (2014). Aboriginal education for non-Aboriginal learners: Engaging teacher candidates in an immersive cultural experience [Doctoral dissertation, University of Toronto].

St. Denis, V. (2010). A Study of Aboriginal Teachers' Professional Knowledge and Experience in Canadian Schools. Canadian Teachers' Federation. 
Styres, S. (2018). Literacies of land: Decolonizing narratives, storying, and literature. In L.T. Smith, E. Tuck, \& K.W. Yang (Eds.), Indigenous and decolonizing studies in education: Mapping the long view (pp. 24-37). Routledge.

Tanaka, M. T. (2016). Learning and teaching together: Weaving Indigenous ways of knowing into education. UBC Press.

Tanaka, M. T. (2009). Transforming perspectives: The immersion of student teachers in Indigenous ways of knowing [Doctoral dissertation, University of Victoria]. http://hdl.handle.net/1828/1664

Tanaka, M., Williams, L., Benoit, Y. J., Duggan, R. K., Moir, L., \& Scarrow, J. C. (2007). Transforming pedagogies: pre-service reflections on learning and teaching in an Indigenous world. Teacher Development, 11(1), 99-109. https://doi.org/ $10.1080 / 13664530701194728$

Toulouse, P. R. (2016). Achieving Indigenous student success: A guide for secondary classrooms. Portage \& Main Press.

Toulouse, P. (2016). What matters in Indigenous education: Implementing a vision committed to holism, diversity and engagement. Measuring What Matters, People for Education.

Truth and Reconciliation Commission of Canada. (2015). Calls to Action. https://nctr.ca/assets/reports/Calls_to_Action_English2.pdf

Tupper, J. (2011). Disrupting ignorance and settler identities: The challenges of preparing beginning teachers for treaty education. In Education, 17(3). https://journals.uregina.ca/ineducation/article/view/71

Vowel, C. (2016). Indigenous writes: A guide to First Nations, Métis, and Inuit issues in Canada. Portage \& Main Press.

Weber-Pillwax, C. (2001). What is Indigenous research? Canadian Journal of Native Education, 25(2), 166.

Williams, L. (2006). Course description for EDCI 499 Fall 2006, Earth Fibres, Weaving Stories: Learning and Teaching in an Indigenous World. [Unpublished document]. University of Victoria.

Wilson, S. (2008). Research is ceremony: Indigenous research methods. Fernwood Publishing. 


\section{Appendix 1}

Post Conference Questionnaire

1. What aspects of Indigenous Education did you know about before attending the workshop series?

2. List the various sessions you attended.

3. What aspects of Indigenous Education do you find challenging to include in your teaching?
a. integrating contemporary Indigenous perspectives
b. Land-based teaching
c. Residential Schools
d. effects of colonialism
e. integrating Indigenous resources into the classroom
f. Calls to Action, Truth and Reconciliation Commission
g. None, I am very comfortable with teaching Indigenous perspectives

4. A. Please list any new things you learned about Indigenous ways of knowing and being, and from which presenter.

B. Explain which, if any, of the following topics were your key take away insights from the workshops:

- Indigenous teachings;

- Indigenous-written resources;

- Asking questions and listening;

- Present challenges;

- Importance of story, culture \& traditions;

- Importance of including Indigenous Education in Faculty of Education courses;

- Importance of Land-based teaching and learning;

- Inviting Indigenous guest speakers into the classroom.

C. What are your thoughts about the presentation format (e.g. storytelling, presentation of material, workshop)?

5. On a scale of 1-5, to what degree did this workshop series broaden your understanding of Indigenous perspectives?

6. What Indigenous topics/issues are you interested in learning more about? 


\section{Appendix 2}

EDU focus group post- virtual presentation survey questionnaire

1. What new insights did you learn from this virtual presentation? (or what resonates with you)?

2. To what degree has this presentation broadened your understanding of Indigenous perspectives?

3. Which information from the presentation, if any, might you like to explore further? Please explain.

4. To what degree has your comfort level with teaching Indigenous perspectives in your future classrooms improved?

\section{Appendix 3}

EDU focus group pre-presentation questionnaire

What aspects of Indigenous Education do you find challenging to include in your lesson planning and teaching?

- Land-based teachings

- The effects of colonization

- The legacy of Residential Schools

- Contemporary Indigenous perspectives

- Other

What are some resources you have found helpful in your teaching/learning of Indigenous Education?

What Indigenous topics/issues are you interested in learning more about?

\section{Appendix 4}

EDU focus group reflection questions on Indigenous-focused mini-lesson design

Provide a brief reflection on the following:

1. The process of having done the Indigenous focused mini-lesson,

2. What prior knowledge you had,

3. The degree of difficulty you had applying this knowledge into a lesson,

4. How effective you think the lesson was,

5. The learning you gained from this activity, and

6. Any next steps? 


\section{BIOGRAPHICAL NOTE:}

Laryssa Gorecki is a lecturer in the Ontario Educational Studies department at the College of Education at Niagara University. She is also an educator with the Toronto Catholic District School Board. Laryssa's research is informed by current and evolving pedagogies that are culturally responsive, equitable, and inclusive, with a focus on decolonizing classroom approaches through relational teaching and learning.

Carol Doyle-Jones, $\mathrm{PhD}$, is an Assistant Professor in the Ontario Educational Studies department, College of Education, Niagara University. Carol's research and teaching centers on uncovering what it means to be an educator in the $21^{\text {st }}$ century. Central to this understanding includes a focus on collaborations, integrating multimodal texts and designs, and the significance of diversity, equity, and inclusion in our culturally and linguistically diverse classrooms. 